\title{
Modeling the Acceptance of Hospital Information Systems among Nurses An Extended Technology Acceptance Model
}

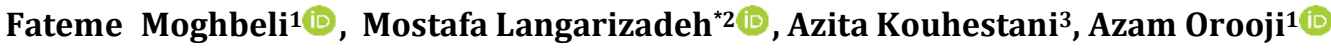

1- PhD Candidate of Medical Informatics, Department of Health Information Management, School of Health Management and Information Sciences, Iran University of Medical Sciences, Tehran, Iran.

2- Department of Health Information Management, School of Health Management and Information Sciences, Iran University of Medical Sciences, Tehran, Iran.

3- MSc in Medical Record Education, Modarres hospital, Shahid Beheshti University of Medical Sciences, Tehran, Iran.

ABSTRACT

Introduction: The perceived usefulness and perceived ease of use have been considered as the main factors affecting the acceptance of the new technologies since last few decades. However, it appears that these only two factors cannot describe the users' behavior in the environments like the Hospital Information System. From the technology acceptance standpoint at the individual acceptance level, the present paper tends to develop a Technology Acceptance Model with introducing some external factors.

Material and Methods: This study was conducted in 2017. The research population was included 185 nurses who works in Health Information Management (HIM) departments of Tehran University of Medical Sciences. A questionnaire was developed in order to gather the required data. The validity was obtained by panel of experts and the reliability was examined and then confirmed in a 50 person sample using the Cronbach's Alpha $(\alpha=0.93)$. The Likert's five item scale was applied. The data were analyzed using descriptive statistics, exploratory factor analysis, and path analysis.

Results: The behavioral intention was affected significantly and positively by the factors of perceived usefulness, perceived ease of use, self-efficacy, end user support, social norm, trust, job relevance, and training, with trust having the highest level of effects. Also perceived ease of use had a significant effect on perceived usefulness along with an indirect effect on behavioral intention through perceived usefulness. The factors of anxiety, voluntariness, and facilitating conditions showed no significant effects on behavioral intention.

Conclusion: The factors of trust, perceived usefulness, social norm, end user support, and self-efficacy have an impact on the behavioral intention of the users utilizing the Hospital Information System in the concerning hospitals. These factors could explain $72 \%$ of the changes of behavioral intention. Concentrating on them would lead to the improvement of the acceptance and Hospital Information System efficiency.

(i) Please cite this article as:

Moghbeli F, Langarizadeh M, Kouhestani A, Orooji A. Modeling the Acceptance of Hospital Information Systems among Nurses: An Extended Technology Acceptance Model. Iran J Med Inform. 2018; 7(1): e1. DOI: 10.24200/ijmi.v7i0.147
Article History

Received: 2018-02-29

Accepted: 2018-04-06

Published: 2018-05-25

Keywords:

Hospital Information System Technology Acceptance Model

Behavioral Intention

Perceived Usefulness

Perceived Ease of Use

* Corresponding Author: M Langarizadeh, School of Health Management and Information Sciences, Iran University of Medical Sciences, Tehran, Iran (Email: langarizadeh.m@iums.ac.ir) 


\section{INTRODUCTION}

The Information Technology (IT) has deeply affected various occupations and social applications. Such kind of technology has occasioned the quality improvement and decreased the administrative costs of different occupations, hence in the health care section $[1, \underline{2}]$. Utilizing the IT in the health care system, especially in the hospitals imbeds several potentials in improving of service quality and personnel efficiency, and decreasing the organizational costs. Many researchers argued that the absence of such new informational systems in the hospitals may lead to inefficiency and the lack of patients' trust $[\underline{3}, \underline{4}]$. Introducing the effective information systems in the health section is considered an undeniable necessity in order to increase efficiency, efficacy, and quality of the services along with the higher customer satisfaction $[\underline{5}, \underline{6}]$.

Data in Hospital Information System (HIS) are stored in a database in such a way that they could be available to the authorized users in the appropriate place and time, with a structure proportional to their special needs. The main goal of the system is to utilize the computers and communicative technologies in order to gather, store, process, extract and connect patient information from different source, and to fulfill the operational needs of the authorized users [7]. Such systems should support the high quality health care services and meet the customers' needs []‥ The quality is mainly discussed in a close relation to the customer satisfaction $[9,10]$. The users have continuous interactions with HIS during their job performance, and their negative attitude towards the system may cause serious challenges for the other groups [11].

The extensive changes of the medical technology along with the growing of patients' expectations have created a considerably increasing need for utilizing HIS. On the other hand, health section experts believe that regarding the information explosion era, the lack of an HIS would weaken the competitive aspects of a hospital $[\underline{12}, \underline{13}]$.

Lorenzi et al. [14], who have performed a large amount of concerning researches consider the people's attitudinalbehavioral limitations and the resistance to the changes among the main limitating factors of the technology systems. Asadi and Mastaneh [15] showed that the factors such as users' primary resistance, shortage of the educational programs, and lack of sufficient motivations among the senior personnel could be considered the main challenges of the human resources management in applying the IT to the hospitals.

Regarding the growing development of technology and the organizational behavior in utilizing the systems, it seems vital to recognize the factors which have an effect on the users' acceptance/resistance, when facing the new information systems and the related security measures. In 1999, the IT costs were estimated to be over one trillion US Dollar per year continuing with an annual $10 \%$ growth, but despite the various enormous investments, several information systems are facing defeat. Hereupon, recognizing the success factors is of great importance [16].

Due to concentrating on the factors such as: profitability and ease of use along with the external factors, the Technology Acceptance Model (TAM) can be regarded as one of the best models to examine the amount of accepting a technology by the users [17]. In the past decades, perceived usefulness and ease of use were considered as the dominant factors in accepting the new technologies in the field of the informational systems. According to a study by Burton Joner from British Colombia University and Hobana from Georgiana University [18], the assumption that these two components perform as the mediators in the external factors may not always be correct and the external factors can directly affect the acceptance or use of the technology. According to Davis [19], we will need more researches in order to examine the other factors' effects on the acceptance.

Algahtani and King [20] believed that capability of recognize, predict, and manage the people's acceptance to use the information systems can be observed as the key factors in the implementation and success of these system. Hung et al. [21], showed that the managerial, organizational, and technical factors have an apparent effect on the technology adoption in the hospitals. Considering the role of the above-mentioned factors in the system acceptance by the users, Tabibi et al. [16], put an emphasis on the hospital authorities' participation in successfully applying the HIS through recognizing the factors affecting the users' intention for using the system.

Nowadays, conducting studies on the technology acceptance in the field of information systems are very prevalent and several models and theories have been under examination and extension [17], but in spite of this fact, merely a few studies have been performed concerning the health section, which indicates a considerable gap in the field, hence the field is open to research yet. Considering the important role of the human factor in improving the HIS efficiency, examining the aforementioned factors can lead to an increasing systematic use of the HIS and consequently, the progress and profitability of an organization. Thus, the need to perform more surveys on the factors concerning the HIS seems very evident.

The present paper would be expected to recognize the principal factors which have an impact on the HIS acceptance in the hospitals affiliated to Tehran University of Medical Sciences on the basis of the TAM.

\section{MATERIAL AND METHODS}

The data collection instrument was a questionnaire developed by the researcher, consisting of 2 divisions: one concerning the respondents' demographic information and the second part consisting of 13 subdivision on the ground of the following factors to be examined: perceived usefulness, perceived ease of use, behavioral intention, trust, result demonstrability, facilitating conditions, job relevance, voluntariness, anxiety, end user support, training, self-efficacy, and social norms. A five grade Likert Scale was used in the questionnaire ( 5 assigned to strongly agree to 1 assigned to strongly disagree).

The validity was obtained by the panel of experts and the reliability was verified by Cronbach's Alpha in a research population of 50 respondents $(\alpha=0.82$ for behavioral intention, $\alpha=0.92$ for perceived usefulness, $\alpha=0.75$ for perceived ease of use, and $\alpha=0.86$ for the external factors) and finally, the total reliability was calculated at $\alpha=0.93$.

The location included hospitals affiliated to Tehran University of Medical Sciences and the research population consisted of 185 personnel with an education background of medical records who worked in the HIM offices of one of those hospitals.

A census method was used in order to gain more valid findings. Out of 185 distributed questionnaires 161 were returned and one was excluded due to some missing values, hence the remaining 160 questionnaire were put to analysis (Showing a response rate of $87.5 \%$ ).

The collected demographic data were analyzed using the descriptive statistics. In order to determine the relationships between the variables, the exploratory factor analysis and the path analysis were applied. The final model was designed using 
the direct and indirect effects between the variables and their role in explaining the behavioral changes of the dependent variables.

At the first stage, the anti-image correlation coefficient (the negative of the partial correlation coefficient) determined the relationship intensity between the variables. Therefore, the scales with a coefficient lower than 0.5 were excluded from the analysis.

The Kaiser-Mayer measure was $\mathrm{KMO}=0.835$. This test was used to evaluate the adequacy of the sample size which turned out to be suitable (very good) [22]. The Bartlett test was used to examine the data appropriateness (BT=7654.239) and the significance level was yielded $(p<0.001)$ [23]. So, it can be concluded that the research data have got an acceptable proportion for the factor analysis test.

The Eigen value was used in this analysis in order to select the number of the factors. According to this criterion, the minimal amount of the Eigen value to select a factor is higher than ' 1 ' and the questions with an Eigen value beneath 0.4 were expunged from the factor analysis. Thus, 15 factors were extracted using a varimax rotation. Regarding all these limitations, 5 scales were crossed out of the analysis. According to the findings, the variance explained by the factors was calculated at 72.58. After detecting the above-mentioned scales, the second factor analysis with 60 questions was carried out to achieve better results. 14 factors were put under observation. Factor 13 with solely one question was excluded from the analysis. Regarding the 60 scales, 12 factors were organized and their Eigen values were calculated (the effect of the factor loading). For instance, the value of the factor loading of question 1 on perceived usefulness was 0.758 , indicating that nearly all the items would acceptably be proportional to the related factor; however, as was mentioned before, some items were omitted (Table 1). Finally, the proposed model was presented (Fig 1).

The Cronbach alpha for each factor was calculated (Table 2). The high reliability resulted from the Cronbach alpha for the factor of perceived usefulness $(0.942)$ suggests that the reliability of the questions concerning the factor of perceived usefulness would be trustful; in other words, the questions measuring the factor of perceived usefulness are relevant and joint in a parallel way. So, in case of swapping the population, the same results would be produced. The average reliability value for the factor of facilitating conditions resulted from Cronbach method (0.243) indicates that the reliability of the concerning questions would be less trustful comparing the other cases (Table 3).

Table 1: Omitted items after factor analysis

\begin{tabular}{|l|}
\hline \multicolumn{1}{|c|}{ Description } \\
\hline I find it easy to get the (HIS) to do what I want to do. \\
\hline (HIS) Does not demand much care and attention. \\
\hline $\begin{array}{l}\text { I would have difficulty explaining why using (HIS) may } \\
\text { or may not be beneficial. }\end{array}$ \\
\hline $\begin{array}{l}\text { I would be more likely to use an (HIS) that I, or a member } \\
\text { of my profession, had been consulted about. }\end{array}$ \\
\hline $\begin{array}{l}\text { I could complete the job using (HIS) if there was no one } \\
\text { around to tell me what to do as I go. }\end{array}$ \\
\hline
\end{tabular}

A path analysis method was used to demonstrate the direct and indirect effect along with the intensity of the effect the independent variable has on the dependent (behavioral intention). In order to that, firstly, the variables were determined:
BI as the dependent variable and the factors of Perceived Usefulness (PU), Perceived Ease Of Use (PEOU), self-efficacy, end user support, social norm, trust, anxiety, voluntariness, job relevance, training, and facilitating conditions as the independent ones and the standard Beta coefficient was calculated for each of them.

As shown in Table 2, the $p$ value is lower than 0.05 for the variables of PU, PEOU, self-efficacy, end user support, social norm, trust, job relevance, and training, indicating a linear relationship between the behavioral intention and the aforementioned factors. On the other hand, the $p$ value is over 0.05 for the variables of anxiety, voluntariness, and facilitating conditions suggesting no such relation (Table 2).

\section{RESULTS}

$91.2 \%$ of the respondents (146) were women and 8.8\% (14) were men. Most of the respondents (52.5\%) were between 30 to 40 years old and most of them had a Bachelor degree (86\%). Most of them were working in the admission unit (42\%) and 55.6\% used the HIS over 6 hours per day. Also, $41.3 \%$ of them used the system for more than 3 times a week. The maximum job background period was between 6 to 15 years $(46.2 \%)$ and the maximum record of the HIS work was between 5 to 10 years (47\%). 105 respondents $(66 \%)$ had an experience of working with the information systems (Table 4).

The path analysis of (Figure1) shows that: there is a linear relation (or effect) between PU and $\mathrm{BI}$ and the former has a positive effect on the latter. $21 \%$ of the changes of BI are influenced by PU. Also there is a linear relation between selfefficacy and Behavioral Intention (BI) and again, the former has a positive effect on the latter. $18.5 \%$ of the changes of BI are under influence by self-efficacy. The results obtained showed that PEOU affects BI positively (10.2\%) and end user support has a positive effect on the BI (9\%) and the two have a linear relation. Social norm has a positive influence on BI (15.4\%) with a linear relation between them. BI is also influenced positively by trust with $25 \%$ of the changes. Their relation is also linear while Anxiety has no effect on the BI, with no linear relation between two. The Voluntariness behaves similar to the factor of anxiety. Both Job Relevance and Training had a positive effect too and their relation with BI was linear of $19 \%$ and $6.5 \%$ of the changes of the latter factor by the former respectively. The factor of facilitating conditions does not affect BI with any linear relation between them however, PEOU positively affects BI (22.4\%), and there is a linear relation between the two.

\section{DISCUSSION}

From the present research, it can be concluded that the factor of PU and social norm would directly affect the users' BI. The result appear to be supported by Tabibi et al. [16], Who showed that the motivational factors have a positive effect on the users' intention to use the HIS, though no effect was shown concerning the factor of PEOU in the latter. 


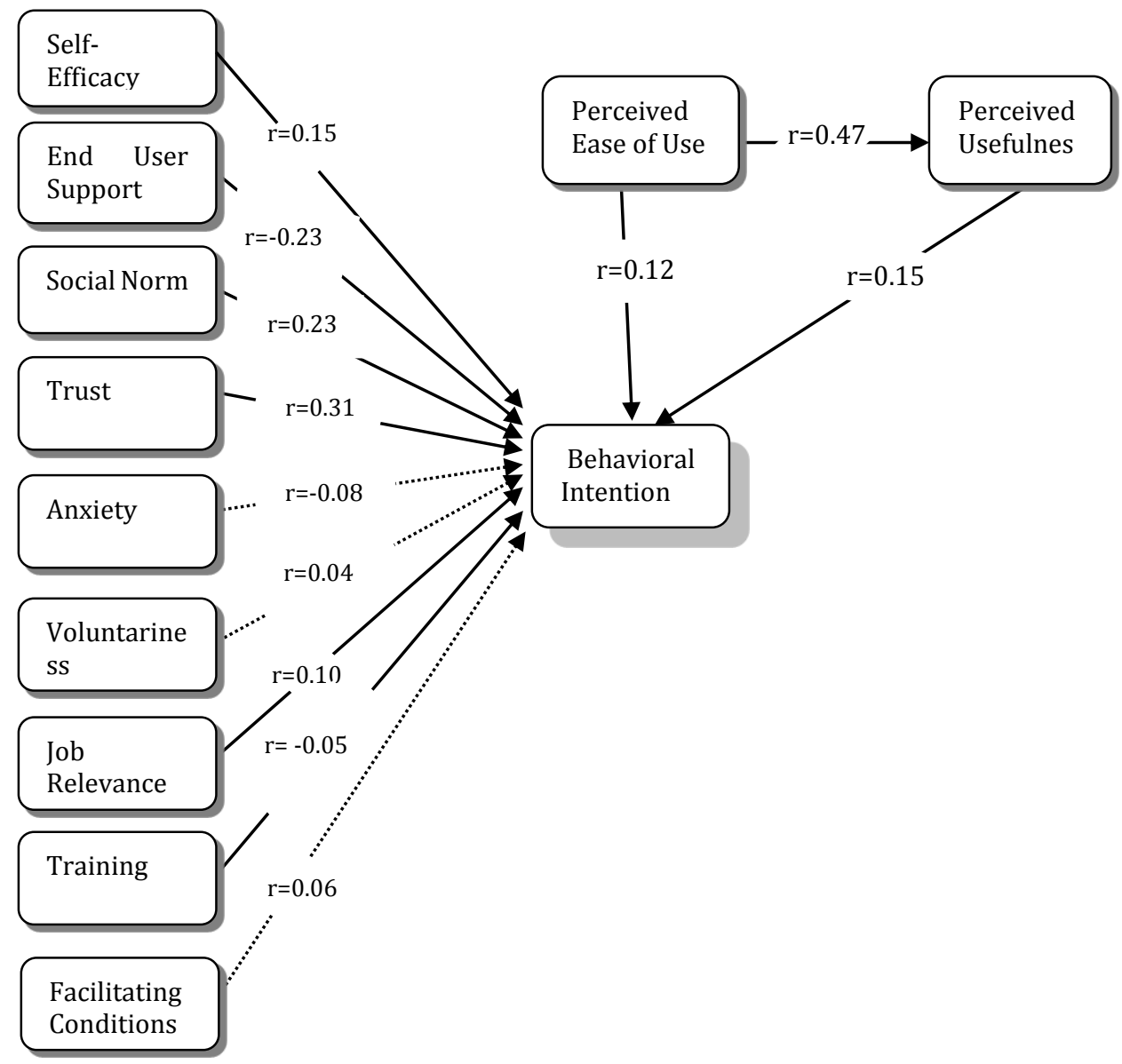

Fig 1: The path coefficient of the research model

Table 2: Path coefficient between independent variable and BI

\begin{tabular}{|l|l|l|l|l|}
\hline \multirow{2}{*}{$\begin{array}{l}\text { Dependent } \\
\text { Factor }\end{array}$} & Independent Factors & $\mathrm{p}$ & $\mathrm{R} 2$ & Beta \\
\hline \multirow{5}{*}{ BI } & PU & 0.001 & 0.209 & 0.184 \\
\cline { 2 - 5 } & PEOU & 0.001 & 0.102 & 0.324 \\
\cline { 2 - 5 } & Self-Efficacy & 0.001 & 0.185 & 0.265 \\
\cline { 2 - 5 } & End User Support & 0.001 & 0.099 & -0.210 \\
\cline { 2 - 5 } & Social Norm & 0.001 & 0.154 & 0.333 \\
\cline { 2 - 5 } & Trust & 0.001 & 0.247 & 0.470 \\
\cline { 2 - 5 } & Anxiety & 0.482 & -0.003 & -0.058 \\
\cline { 2 - 5 } & Voluntariness & 0.808 & -0.006 & -0.031 \\
\cline { 2 - 5 } & Job Relevance & 0.001 & 0.186 & 1.05 \\
\cline { 2 - 5 } & Training & 0.001 & 0.065 & 0.305 \\
\cline { 2 - 5 } & Facilitating Conditions & 0.097 & 0.011 & 0.290 \\
\hline PEOU & PU & 0.001 & 0.224 & 0.479 \\
\hline
\end{tabular}


Table 3: Reliability of scale measures

\begin{tabular}{|l|l|}
\hline Factors & Cronbach's Alpha \\
\hline Perceived Usefulness & 0.942 \\
\hline Behavioral Intention & 0.902 \\
\hline Self-Efficacy & 0.875 \\
\hline Job Relevance & 0.876 \\
\hline Perceived Ease of Use & 0.858 \\
\hline End user Support & 0.857 \\
\hline Social Norm & 0.857 \\
\hline Trust & 0.843 \\
\hline Training & 0.759 \\
\hline Anxiety & 0.753 \\
\hline Voluntariness & 0.807 \\
\hline Facilitating conditions & 0.243 \\
\hline
\end{tabular}

Our findings also tend to correspond to those of Wu et al. [24], which suggest the effect of PU and social norm on the health care professionals' intention to use an adverse event reporting system. Also, a conformity can be seen between the present survey and a study by Mohaghar et al. [25], showing the effect of social norm on the technology acceptance in the ministry of interior affairs.

The result of this research can also be confirmed by those of $\mathrm{Wu}$ et al. [24], Morton [26], Sheikhshoaei and Oloumi [27] and Tabibi [16] which have put an emphasis on the relation between PEOU and PU. However, Soleimani [28], suggested that the factor of PU would have no effect on the intention of the students of the agricultural vocational schools towards accepting the IT, which might probably be due to a different research population.

The relation of self-efficacy and BI was also confirmed, as was shown earlier by Monzavi and Zarei [29], who emphasized the impact of self-efficacy on the users' BI to use the Project Information System (PIS)

Our results also correspond to those of Tung et al. [이 ], which showed the positive effects of trust and PU on the nurses' intention adoption of the electronic logistics information system in HIS. Although, opposite to our findings, the later also emphasized the effects of PU.

Aggelidis [3], suggested the impact of PU, social norm and selfefficacy on the BI of the personnel of the Greek hospitals to use the HIS, conforming to our research as for the second and third factors.

As for the effects of end user support on the BI to utilize the HIS, our results are comparable with those of Can [1ㅡ] and Kowitlawakul [32], which predicted the same effects on the users' $\mathrm{BI}$ to use the HIS and on the nurses' intention to use telemedicine technology. That PEOU would not affect BI was already shown by Chismar and Willey-Patton [33] and Bertrand and Bouchard [34].
Table 4: The respondents' demographic characteristics

\begin{tabular}{|c|c|c|}
\hline Features & \multicolumn{2}{|c|}{ Description of the Respondents } \\
\hline \multirow{2}{*}{ Gender } & Male & $8.8 \%$ \\
\hline & Female & $91.2 \%$ \\
\hline \multirow[t]{3}{*}{ Age } & $23-29$ & $36.7 \%$ \\
\hline & $30-40$ & $52.5 \%$ \\
\hline & over 40 & $10.8 \%$ \\
\hline \multirow[t]{3}{*}{ Education } & Associate & $10.8 \%$ \\
\hline & Bachelor & $86.1 \%$ \\
\hline & Master & $3.2 \%$ \\
\hline \multirow{4}{*}{ Work unit } & Statistics & $11.5 \%$ \\
\hline & Coding & $15.4 \%$ \\
\hline & Filing & $31.4 \%$ \\
\hline & Admission & $41.7 \%$ \\
\hline \multirow{6}{*}{$\begin{array}{l}\text { Hours of HIS } \\
\text { work per day }\end{array}$} & Under 1 hour & $5.6 \%$ \\
\hline & 1-2 hours & $11.3 \%$ \\
\hline & $2-4$ hours & $7.5 \%$ \\
\hline & 4-6 hours & $16.9 \%$ \\
\hline & over 6 hours & $55.6 \%$ \\
\hline & 0 hour & $3.1 \%$ \\
\hline \multirow{6}{*}{$\begin{array}{lr}\text { Frequency } & \text { of } \\
\text { HIS work per } \\
\text { day }\end{array}$} & Once a day & $9.7 \%$ \\
\hline & 2-3 times a day & $32.9 \%$ \\
\hline & once a week & $4.5 \%$ \\
\hline & 2-3 times a week & $7.1 \%$ \\
\hline & over 3 times a week & $41.3 \%$ \\
\hline & no work & $4.5 \%$ \\
\hline \multirow[t]{4}{*}{ Job Background } & Under 5 years & $18.4 \%$ \\
\hline & 6-15 years & $46.2 \%$ \\
\hline & 16-25 years & $28.5 \%$ \\
\hline & over 25 years & $7 \%$ \\
\hline \multirow{4}{*}{$\begin{array}{l}\text { HIS Work } \\
\text { Experience }\end{array}$} & Under 5 years & $44.3 \%$ \\
\hline & 6-15 years & $47 \%$ \\
\hline & $16-25$ years & $5.4 \%$ \\
\hline & over 25 years & $3.3 \%$ \\
\hline \multirow{2}{*}{$\begin{array}{l}\text { Work } \\
\text { Experience with } \\
\text { the other } \\
\text { Informational } \\
\text { Systems }\end{array}$} & Yes & $66 \%$ \\
\hline & No & $34 \%$ \\
\hline
\end{tabular}

\section{CONCLUSION}

The results of the present research can be confirmed by a large number of similar researches on the technology acceptance. The findings can assist the hospital managers with the comprehensive use of the HIS and its success, through recognizing the factors which have an influence on the users' BI. The fact that a difference did not achieve statistical significance does not mean there was no difference. Therefore, this study may affected from imbalanced population in order to some variables such as gender which was the most important limitations of our study.

\section{REFERENCES}

1. Abedian S, Bitaraf E. Offering model of hospital information system. Statistics and Information Technology Management Center of Ministry of Health and Medical Education 2009.

2. Langarizadeh M, Moghbeli F, Aliabadi A. Application of Ethics for Providing Telemedicine Services and Information 
Technology. Medical Archives. 2017; 71(5): 351-5. PMID: $29284905 \quad$ DOI: $\quad 10.5455 /$ medarh.2017.71.351-355 [PubMed]

3. Aggelidis VP, Chatzoglou PD. Using a modified technology acceptance model in hospitals. Int J Med Inform. 2009; 78(2): 115-26. PMID: $18675583 \quad$ DOI: 10.1016/j.ijmedinf.2008.06.006 [PubMed]

4. Helia VN, Asri VI, Kusrini E, Miranda S, editors. Modified technology acceptance model for hospital information system evaluation-a case study. MATEC Web of Conferences; 2018: EDP Sciences. DOI: 10.1051/matecconf/201815401101

5. Yousefi M, Moradi GH, Ghazisaeidi M, Fazaeli S. Review of various aspects of clinical information systems implementation and awareness of health information administrators about it. Health Information Management. 2011; 8(2): 1-10.

6. Rootes-Murdy K, Glazer KL, Van Wert MJ, Mondimore FM, Zandi PP. Mobile technology for medication adherence in people with mood disorders: A systematic review. Journal Affect Disord. 2018; 227: 613-7. PMID: 29172054 DOI: 10.1016/j.jad.2017.11.022 [PubMed]

7. Ebadifardazar F, Ansari H, Zohour A, Marashi S. Study of users attitudes about the computerized hospital information systems (HIS) in hospitals of Tehran. Payesh Journal 2006; 6(1): 11-8.

8. Gozali E, Langarizadeh M, Sadooghi F, Sadeghi M. Electronic medical record, step toward improving the quality of healthcare services and treatment provided to patients. J Ardabil Univ Med Sc. 2014; 14(1): 93-6.

9. Kimiyafar KH. A study of users views about hospital information system quality in teaching hospitals of Mashhad University of medical sciences. [M.S Thesis in Persian]. Tehran: Iran University of Medical Sciences; 2006.

10. Bull S, Thomas DS, Nyanza EC, Ngallaba SE. Tanzania health information technology (T-HIT) system: Pilot test of a tabletbased system to improve prevention of mother-to-child transmission of HIV. JMIR Mhealth and Uhealth. 2018; 6(1): e16. PMID: 29335236 DOI: 10.2196/mhealth.8513 [PubMed]

11. Foster RS. Human factors in health information systems: The Western Cape experience. Department of the Premier: Provincial Government of the Western Cape; 2005

12. Mooseli L. Hospital information system (HIS). The abstract articles of the sixth conference of health care management students; Tehran. 2008.

13. Hajavi A, Hoseini F, Langarizadeh M. Usability condition of medical records department's software packages at medical universities' hospitals in Tehran. Journal of Health Management. 2002; 7(17): 12-6.

14. Lorenzi NM, Riley RT, Dewen N. Barriers and ressistance to informatics in behavioral health. Stud Health Technol Inform. 2001; 84(Pt 2): 1301-4. PMID: 11604938 [PubMed]

15. Asadi F, Mastaneh Z. Challenges of using information technology in hospitals affiliated to Shahid Beheshti University of medical sciences. Iranian Journal of Surgery. 2012; 20(1): 18-26.

16. Tabibi J, Nasiripour AA, Baradaran Kazemzadeh R, Farhangi AA, Ebrahimi P. Effective factors on hospital information system acceptance: A confirmatory study in Iranian hospitals. Middle-East Journal of Scientific Research. 2011; 9(1): 95-101.

17. Venkatesh V, Morris MG, Davis FD, Davis G. User acceptance of information technology: toward a unified vie. MIS Quarterly. 2003; 27(3): 425-78.

6
18. Bagheri MA, Hamidi Beheshi MT, Alidousti S. Acceptance of internet banking in Iran: Extension of technology acceptance model (TAM). Iranian Journal of Information Processing and Management. 2009; 24(3): 5-33.

19. Davis FD. Perceived usefulness, perceived ease of use, and user acceptance of information technology. MIS Quarterly. 1989; 13(3): 319-39.

20. Algahtani SS, King M. Attitudes, satisfaction and usage: factors contributing to each in the acceptance of information technology. Behavior and Information Technology. 1999; 18(4): 277-97.

21. Hung SY, Hung WH, Tsai CA, Jiang SC. Critical factors of hospital adoption on CRM System: organizational and information system perspectives. Decision Support Systems. 2010; 48: 592-603.

22. Williams B, Brown T, Onsman A. Exploratory Factor Analysis: A Five-Step Guide for Novices. Australasian Journal of Paramedicine. 2010; 8(3): 1-13.

23. Crawford J. Interpretation of eigenvalues in multivariate statistical analysis and Bartlett's test for Riesz distributions. Indiana: Indiana University 2008.

24. Wu JH, Shen WS, Lin LM, Greenes RA, Bates DW. Testing the technology acceptance model for evaluating healthcare professionals, intention to use an adverse event reporting system. Int J Qual Health Care. 2008; 20(2): 123-9. PMID: 18222963 DOI: $10.1093 /$ intqhc/mzm074 [PubMed]

25. Mohaghar A, Shirmohammadi M. Developing of TAM in ministry of interior affairs. Journal of Knowledge Management. 2004; 17(5):113-31.

26. Morton ME. Use and acceptance of an Electronic health record: factors affecting physician attitudes [M.S Thesis]: Drexel; 2008.

27. Sheikhshoaei F, Oloumi T. A study of effective factors on information technology acceptance by librarian of technical college libraries of Tehran public universities. Library \& Information Sciences. 2007; 10(3): 9-34.

28. Soleimani A, Zarafshani K. Factors determining adoption of information technology by vocational agricultural teaches using technology acceptance model (TAM) in Kermanshah province. Iranian Journal of Information Processing and Management. 2011; 26(4): 885-902.

29. Monzavi T, Zarei B. Designing a model to explicate factors influence the process of IT user adoption: A research about Iranian offshore engineering and construction company. Journal of Information Technology Management. 2010; 2(5): 129-48.

30. Tung FC, Chang SC, Chou CM. An extension of trust and TAM model with IDT in the adoption of the electronic logistics information system in HIS in the medical industry. Int J Med Inform. 2008; 77(5): 324-35. PMID: 17644029 DOI: 10.1016/j.ijmedinf.2007.06.006 [PubMed]

31. Can P. An analysis of the main critical factors that affect the acceptance of technology in hospital management systems [M.S Thesis]. Turkey: Univ. Middle East Technical; 2010.

32. Kowitlawakul Y. The technology acceptance model: Predicting nurses' intention to use telemedicine technology. Comput Inform Nurs. 2011; 29(7): 411-8. PMID: 20975536 DOI: $10.1097 /$ NCN.0b013e3181f9dd4a [PubMed]

33. Chismar WG, Willey-Patton S, editors. Test of the technology acceptance model for the internet in pediatrics. The 36th Hawaii international conference; 2003; Honolulu: Management Science Hawaii.

34. Bertrand M, Bouchard S. Applying the technology acceptance model to VR with people who are favorable to its use. Cybertherapy \& Rehabilitation. 2008; 1: 200-10. 